\title{
ÉTICA ORIGINÁRIA: UMA REFLEXÃO PARA ALÉM DE TEORIA E PRÁTICA
}

\author{
Marcos André Webber ${ }^{1}$ \\ Universidade do Vale do Rio dos Sinos (UNISINOS) \\ (D) https://orcid.org/0000-0003-3024-9133
}

\begin{abstract}
RESUMO:
O presente artigo tem como objetivo justificar que a concepção de ética originária desenvolvida por Heidegger, alinhada à importância que Gadamer atribui à experiência particular, pode trazer uma relevante contribuição para a reflexão filosófica acerca dos temas que envolvem a ética, como tentativa de superação do modo tradicional de se conceber a própria ética enquanto tal. A forma pela qual a tradição metafísica tem historicamente abordado o tema da ética reforça a distinção entre teoria e prática, e a busca de princípios ou normas universalmente aplicáveis tem se mostrado insuficiente para elucidar o que torna possível a experiência moral. A linguagem conceitual generalista, da mesma forma, tem se demonstrado inadequada para tratar do tema, visto que tende a aproximar a ética da técnica própria das ciências, ignorando a relevância que a experiência particular pode trazer para o debate ético. Nesta perspectiva, a ética originária fornece elementos para a construção de um sentido de ética que almeja alcançar a singularidade da existência, superando assim a distinção entre teoria e prática, e colocando em evidência uma instância prévia, que permaneceu oculta em razão dos limites da própria metafísica.
\end{abstract}

PALAVRAS-CHAVE: Ética originária; Experiência; Técnica; Singularização.

\section{ORIGINARY ETHICS: A REFLECTION BEYOND THEORY AND PRACTICE}

\begin{abstract}
:
This paper aims to justify that the idea of an originary ethics, as developed by Heidegger, combined with the importance that Gadamer attaches to private experience, may provide a relevant contribution to philosophical reflection on issues concearning ethics, as an attempt to overcome the traditional way of conceiving ethics as such. The way whereby metaphysical

\footnotetext{
${ }^{1}$ Doutorando em filosofia pela Universidade do Vale do Rio dos Sinos (UNISINOS), Rio Grande do Sul - Brasil. E-mail: marcoswebber@terra.com.br.
} 
tradition has historically addressed ethics enhaces the distinction between theory and practice, and the search of principles or rules universally applicable has shown insufficient to clarify what makes moral experience possible. The generalist conceptual language, as well, has shown inappropriate to address the subject, once it tends to bring ethics close to technique related to science, ignoring the relevance that private experience may bring to ethical debate. In this perspective, originary ethics provides elements to establish a meaning for ethics able to reach the singularity of existence, overcoming the distinction between theory and pratice, and putting in evidence a prior instance, that remained concealed due the limits of metaphysics itself.

KEYWORDS: Original ethics; Experience; Technique; Singularization

\section{Considerações Iniciais}

Em grande medida, a relação que o homem mantém com o mundo e consigo mesmo está ligada ao conhecimento que o homem adquire, seja do próprio mundo ou de si mesmo. As fontes da produção do conhecimento podem ser variadas, assim como são diversas as visões de mundo e os modos de ser que o homem vem a assumir em tal relação. Há certamente uma gama de conhecimentos cujas implicações alcançam a dimensão ética da existência, e compreendê-los pode ajudar a elucidar as exigências que o modo de ser ético impõe sobre o comportamento do homem enquanto serno-mundo.

Neste contexto, o presente trabalho tem como objetivo principal justificar que a concepção de ética originária desenvolvida por Heidegger pode trazer uma importante contribuição para o estudo da ética, apresentando-se como uma tentativa de superação do modo tradicional de se conceber a ética. Ao passo que o modo pelo qual a tradição metafísica tem abordado o tema da ética reforça a separação entre teoria e prática, voltando suas atenções para a busca de princípios ou normas universalmente aceitas, com a pretensão de justificar as ações morais, observa-se que as questões que dizem respeito à ética ocorrem em situações singulares. O desafio está justamente em construir uma compreensão da ética capaz de alcançar a singularidade que caracteriza a existência e a vida prática, de onde as questões éticas comumente emergem.

Para tanto, o presente trabalho se desenvolverá em três partes. Inicialmente será apresentada a distinção feita por Gadamer entre técnica e prática, destacando-se a importância da experiência particular para os temas próprios da ética. A seguir serão trazidas algumas críticas à forma pela qual a tradição metafísica tem abordado o tema da ética, especialmente no que diz respeito à pretensão de universalização de máximas ou regras universais,

Ética originária: uma reflexão para além de teoria e prática - Marcos André Webber 
e à consequente objetificação de vida fática. Em um momento final, buscarse-á justificar, na esteira da análise proposta por Dennis J. Schmidt, que a ética originária heideggeriana pode fornecer elementos capazes de superar a concepção de ética em termos de teoria e prática, e com isso alcançar a singularidade da existência, possibilitando assim uma ampliação da reflexão filosófica sobre o tema, não apenas no que diz respeito às possíveis relações entre ética e existência, mas no sentido do que seja a ética enquanto tal.

\section{Técnica, prática e a experiência particular}

No capítulo Teoria, técnica, prática, que compõe a obra El estado oculto de la salud, Gadamer (2001) promove uma reflexão sobre a distinção entre o conhecimento produzido pela ciência e o conhecimento proveniente da experiência particular de cada ser humano. Enquanto diferentes fontes de conhecimento, cada uma delas desvela algo sobre o mundo. Assim, se de um lado há um conhecimento puramente objetivo, proporcionado pelas ciências e pelo avanço científico, de outro há um tipo de conhecimento subjetivo, fruto da contínua experiência que o homem tem de si mesmo e dos outros seres humanos.

Há que se observar, dentro da distinção proposta por Gadamer, que o conhecimento decorrente da experiência particular não deve ser deixado de lado na análise das questões éticas. E isso se justifica por dois motivos: $a$ ) a adequada compreensão das implicações do conhecimento particular coloca em evidência os limites da ideia de ética enquanto um conjunto de regras universais, visto que a aproxima da técnica, ao invés que concebê-la como uma prática; $b$ ) a inclusão do conhecimento particular aproxima o debate ético da singularidade da vida na qual as questões éticas emergem.

Muito embora fale-se de aplicação da ciência, Gadamer ressalta que esta não deve ser compreendida como uma prática. Isso porque ambas não são idênticas, ainda que determinada prática implique a aplicação da ciência. É que a prática não significa apenas fazer o que se pode fazer, pois leva em conta também o conhecimento particular do agente. Enquanto que a experiência científica, uma vez garantida pelo método científico, possui independência quanto à situação prática e ao contexto de ação, bastando um procedimento metodológico, na prática cotidiana está sempre envolvido um conhecimento que provém da experiência particular, e que não pode ser descartado na compreensão do comportamento ético.

Ocorre que o tipo de conhecimento produzido pela ciência é orientado para um poder-fazer que se traduz em uma técnica, visto que se efetiva através da aplicação de uma teoria. Já a prática, por sua vez, requer o conhecimento particular do agente, que é um elemento que o singulariza frente ao universal. Assim, ao tomar uma decisão, na prática o agente não aplica simplesmente uma teoria, mas recorre também à sua experiência

Ética originária: uma reflexão para além de teoria e prática - Marcos André Webber 
frente a situações concretas passadas. Como bem esclarece Gadamer, "a prática é sempre, também, eleição de decisão entre possibilidades. Sempre guarda uma relação com o 'ser' do homem" (GADAMER, 2001, p. 16).

Neste contexto, a questão volta-se às condições de possibilidade de se produzir um saber sobre o agir ético enquanto tal. Ao analisar a ética aristotélica, Gadamer demonstra especial preocupação em explicitar o modo pelo qual o filósofo grego diferencia o saber ético da techne:

Uma techne se aprende, e pode também ser esquecida. Mas o saber ético não pode ser aprendido e nem esquecido. Não nos confrontamos com ele ao modo de poder apropriar-nos ou não dele, como podemos escolher ou deixar de escolher uma habilidade objetiva, uma techne. Ao contrário, encontramo-nos sempre na situação de quem precisa atuar (com abstração feita da fase da menoridade, na qual a obediência ao educador substitui a decisão pessoal) e, assim, já devemos sempre possuir e aplicar o saber ético. Por isso o conceito da aplicação é tão problemático, pois só se pode aplicar o que já se possui previamente. Mas não possuímos o saber ético para nós mesmos de forma a primeiro possuí-lo para depois aplicá-lo à situação concreta. (GADAMER, 2011, p. 417-418)

Ocorre que o saber ético, embora igualmente prévio, não é o mesmo tipo de saber que possui o artesão que sabe produzir coisas determinadas. Enquanto que o saber técnico deve ser algo ensinado, o saber ético não é suscetível de aprendizagem, visto que não existe uma determinação prévia daquilo sobre o que se orienta a vida no seu todo. O saber ético, em última instância, exige um certo tipo de experiência que não é passível de ser ensinada. Conforme explica Gadamer,

O saber ético é verdadeiramente um saber peculiar. Abrange de modo especial os meios e os fins e com isso distingue-se do saber técnico. Por isso não faz muito sentido distinguir aqui entre saber e experiência, o que, por sua vez, convém perfeitamente à techne. $\mathrm{O}$ saber ético contém por si mesmo um certo tipo de experiência. (GADAMER, 2011, p. 424)

Dessa forma, Gadamer ajuda-nos a compreender que a dimensão do comportamento humano relevante para a reflexão ética deve estar ligada a uma certa prática, que não se limita à aplicação de regras ou princípios abstratos universais, sob pena de se reduzir a uma técnica. Enquanto que o saber técnico pode ser ensinado ao outro, chegando-se aos mesmos resultados, a produção do saber ético está diretamente associado à experiência particular de cada um, e nesse sentido singulariza o agente. E na medida em que as questões éticas nascem em situações da vida particular, denota-se a dificuldade das concepções tradicionais da ética filosófica em 
explicar como conciliar a universalização dos princípios com a singularidade da experiência ética.

Carel (2014) chama a atenção para o fato que a doença pode modificar a interação que temos com os objetos e com o ambiente, provocando uma transformação tanto no nosso comportamento como na compreensão que temos da realidade. Assim, ao mesmo tempo em que o advento de uma doença pode ser convite para o filosofar, ela propicia um tipo de experiência do mundo e da própria vida muito particulares, que singularizam a existência, e por isso não devem ser afastadas na abordagem de questões éticas. A experiência particular pode propiciar uma compreensão da realidade que passa a servir como uma espécie de guia para o comportamento, mas que nem sempre se coaduna com princípios e normas universalizáveis.

Nesse mesmo sentido, observa Dreyfus:

[...] mesmo se duas situações fossem idênticas em tudo, dois experts em ética com diferentes histórias não responderiam necessariamente da mesma forma. Cada pessoa deve simplesmente responder assim como ele ou ela pode a cada situação única apenas com a sua intuição baseada na experiência como guia. Heidegger captura esta habilidade ética em sua noção de cuidado autêntico como uma resposta à situação única, como oposta à situação geral. (DREYFUS, 1990, 19)

Embora não utilize os mesmos termos de Gadamer, Dreyfus também destaca a importância da experiência particular do agente na resposta às situações que envolvem a ética. Nesta perspectiva, a busca de regras e princípios universais dá lugar a um modo de compreender a ética mais perto das situações da vida nas quais as questões éticas surgem.

Pois esta é justamente a proposta de Dennis J. Schmidt, em sua tentativa de trazer a ética mais perto das suas fontes, e mostrando a necessidade de superar a concepção da ética enquanto aplicação de uma teoria. Pautado-se no que Heidegger veio a chamar de ética originária, Schmidt (SCHMIDT, 2012, p. 35) sugere que a ética deveria ser vista de uma maneira diferente, e que reflita a superação da distinção entre teoria e prática que por um longo tempo governaram a reflexão ética. Assim, antes de se avançar na análise do significado da ética originária, torna-se fundamental apontar os limites da metafísica na abordagem do tema proposto.

\section{Os limites da metafísica frente à ética}

Historicamente, a reflexão filosófica promovida pela tradição

Ética originária: uma reflexão para além de teoria e prática - Marcos André Webber

Griot : Revista de Filosofia, Amargosa, Bahia - Brasil, v.14, n.2, dezembro/2016/www.ufrb.edu.br/griot 
metafísica tem se voltado à busca de regras ou princípios universais capazes de justificar a ação ética e a ação não ética. Se tomarmos as grandes correntes do pensamento ético-filosófico, é possível perceber a tentativa de criação de princípios universalmente válidos, os quais, se observados pelo agente, trariam a certeza de um comportamento ético. Seja através da observação das máximas da razão, no modelo kantiano, ou pelo cálculo de felicidade utilitarista, o fato é que tais formas de compreender a ética aproximam-se do que Gadamer definiu como sendo uma técnica, em clara oposição à prática. Na medida em que as correntes metafísicas da filosofia moral passam a prescrever normas de conduta (teoria), e que ao homem cabe apenas a aplicação de tais normas pré-estabelecidas (prática), o modelo ético construído pela tradição se assemelha ao modelo comumente atribuído às ciências.

Há, contudo, algumas limitações neste modo de compreender a ética, que a torna insuficiente para dar conta das questões a que se propõe. Embora não seja o objetivo do presente trabalho aprofundar esta questão, torna-se importante indicar algumas destas limitações, justamente para que se possa justificar os motivos pelos quais a ética originária pode contribuir para a reflexão acerca do tema.

Dessa forma, a relevância da experiência particular em relação à ética permite colocar em evidência duas questões que mostram as limitações das concepções metafísicas de ética: $a$ ) na medida em que a ética pode ser traduzida em regras ou princípios universais, mas as questões éticas sempre surgem em situações particulares, como conciliar a pretensão de universalidade com a exigência particular da vida fática?; e $b$ ) como explicar a relação da ética com a singularidade da vida fática, se a linguagem utilizada está sempre voltada para a universalização dos princípios?

Note-se que no centro da discussão encontra-se o problema da aplicação sempre particular de normas e princípios que pretendem ser universalizáveis. Aceitar que a aplicação das normas éticas deveria se dar de forma análoga à aplicação das leis científicas significaria ignorar a relevância da experiência particular dos seres humanos, sua capacidade de decisão e sua liberdade. E mais do que isso, pode-se dizer que reduzir a ética a uma espécie de técnica significaria promover uma objetificação da vida, e negar a cada ser humano aquilo que o distingue dos demais.

Pelo contrário, a reflexão ética deveria voltar-se para o resgate da experiência moral que se dá na singularidade da vida fática, e nesse sentido é preciso levar em consideração a compreensão que o homem tem de si mesmo e do mundo. É que a compreensão, especialmente se tomada sob uma perspectiva hermenêutica, já representa um retorno à vida fática que atribui sentido ao mundo. Conforme explicita Gadamer, na compreensão não é preciso estabelecer previamente uma teoria, uma vez que a

Ética originária: uma reflexão para além de teoria e prática - Marcos André Webber 
compreensão já é aplicação: "não se trata de uma aplicação ulterior de algo já compreendido em si mesmo a outra coisa distinta, mas a própria aplicação é a autêntica compreensão do assunto para aquele que tenta compreender" (DUTT, 1998, p. 41). Neste contexto, a aplicação não deve ser entendida como um objetivo da práxis hermenêutica, mas como um elemento implícito em toda compreensão. Quem compreende forma parte da mesma coisa que compreende.

Pois esta seria justamente a tarefa da hermenêutica: superar a noção de que a compreensão precisa ser aplicada. Como esclarece Schmidt,

a compreensão nunca é encontrada separada da vida fática; ela não se coloca acima dela como uma teoria, mas nem deve ser definida como uma questão de práxis. Preferivelmente, a compreensão é um ato contínuo que é renovado a todo instante; é um modo de vida que é informado pela história, linguagem e hábitos - todas as realidades da situação da vida fática. Enquanto tal, a compreensão não deve ser compreendida como uma teoria - embora uma teoria possa eventualmente resultar da compreensão - nem deve ser compreendida como uma ação [...]. Preferivelmente, a compreensão forja o centro, o "quem", que nos tornamos; ela se torna a base para como é que passamos a conhecer e articular conceitualmente nosso mundo e a nós mesmos. (SCHMIDT, 2012, p. 42)

A dificuldade na compreensão deste retorno à vida fática, que não deve ser entendido como uma mera aplicação de uma teoria, está justamente no fato que ele não pode ser descrito a partir da linguagem e da lógica do conceito. É que a linguagem conceitual, na visão de Schmidt, mostra-se insuficiente e inadequada para a linguagem da vida ética, exigindo espaço para uma nova relação com a linguagem:

O problema com o conceito é este: ele é definido pelo impulso, pelo ímpeto, à universalidade e generalidade, mas a vida ética é vivida na vida do idioma - nas realidades da história, os sofrimentos dos indivíduos, e nas singularidades que definem a vida como um idioma, como um ente singular que é absolutamente responsável por como compreende o seu mundo e como estabelece esta compreensão. (SCHMIDT, 2012, p. 40)

Ao referir-se à singularidade da vida como um idioma, Schmidt está chamando a atenção para o cuidado que se deve ter quanto à linguagem utilizada para descrever a vida fática. Se por um lado o autor desfere fortes críticas à linguagem universalista e generalista da tradição metafísica, por outro ele quer mostrar que a vida fática exige uma linguagem própria, ou, no termo que utiliza, seu próprio idioma. Sem ele, a tentativa de explicação da vida singular fica refém de generalizações que limitam o alcance da própria

Ética originária: uma reflexão para além de teoria e prática - Marcos André Webber 
reflexão filosófica.

E baseada nesta linguagem conceitual, a abordagem da ética feita pela tradição metafísica se expressa em termos que muitas vezes se aproximam da linguagem universalizável do direito, especialmente ao fazer referência a normas, leis e princípios. $\mathrm{E}$ mesmo concepções de certo e errado, culpa e inocência, bem e mal, têm como pano de fundo uma articulação de termos jurídicos que não tem o poder de explicar a singularidade da vida fática. Talvez a linguagem mais apropriada para propiciar a abertura da existência a questões éticas seja a literatura e as artes, motivo pelo qual Schmidt menciona uma frase de Heidegger acerca da ética: "as tragédias de Sófocles ocultam - permita-se-me uma tal comparação -, em seu dizer, o ethos, de modo mais originário que as preleções de Aristóteles sobre a 'Ética"'. (HEIDEGGER, 1973, p. 368)

Ao utilizar o termo "originário", Heidegger não apenas rompe com o sentido de ética estabelecido pela tradição metafísica, como também indica que a ética deve ser compreendida em sua relação com a ontologia e com o ser. Conforme ressalta Loparic (2004, p. 55-56), Heidegger é claro, em Ser e tempo, ao interpretar o agir moral prescrito pela ética tradicional como um agir causal, e, consequentemente, um tipo de agir técnico. Pois esta é uma das razões pelas quais o filósofo alemão evita utilizar o termo "ação", substituindo-o por "ocupação preocupada". Assim, antes da análise de normas ou princípios atemporais, é preciso compreender o modo a partir do qual o Dasein atribui sentido ao mundo, a si mesmo e à ética. Trata-se, portanto, de uma esfera da existência que antecede - e por isso mesmo pretende superar - a distinção entre teoria e prática, e que se mostra condição de possibilidade para uma possível relação entre ética e existência.

\section{Ética originária e o sentido do habitar}

Revelando ter sido questionado sobre quando escreveria ele uma ética, Heidegger adverte que, "antes de procurarmos determinar mais exatamente as relações entre 'a Ontologia' e 'a Ética', devemos perguntar o que são a própria 'Ontologia' e a própria 'Ética'" (HEIDGGER, 1973, p. 367). Muito embora possa passar despercebida, a dificuldade que cerca a determinação das relações entre ontologia e ética reside no fato de que Heidegger situa a ética na dimensão ôntica da existência. Assim como as ciências empíricas, a ética se refere a uma região do ente, enquanto que a ontologia fundamental desenvolvida em Ser e tempo busca explicitar a relação do Dasein com o sentido do ser. Desse modo, tratar do tema da ética sob a perspectiva heideggeriana exige antes elucidar a estrutura existencial que o ser-ético ontologicamente requer.

Importa, nesta perspectiva, perceber que o Dasein possui uma dimensão pré-reflexiva, ontológica, e que permaneceu oculta da tradição

Ética originária: uma reflexão para além de teoria e prática - Marcos André Webber 
metafísica em razão dos limites da própria metafísica. E é por isso que uma adequada compreensão da ética em suas relações com a ontologia podem ampliar a reflexão filosófica sobre o tema, não apenas quanto ao que torna possível a experiência moral, mas também ao próprio sentido do que seja a ética enquanto tal. Em que pese o visível crescimento do interesse em empreender esforços no sentido de aproximar a filosofia heideggeriana dos temas próprios da filosofia moral, o fato é que as implicações do pensamento de Heidegger no campo da ética filosófica constitui-se ainda um trabalho a ser realizado. Isso porque, se considerarmos que de fato há uma dimensão ética na filosofia heideggeriana, trata-se de uma concepção diversa daquela pela qual a tradição tem historicamente abordado as questões éticas e morais. Isso é o que destaca Nancy, ao mencionar que

$$
\begin{aligned}
& \text { não há "moralidade" em Heidegger se o que se considera por } \\
& \text { isso é um corpo de princípios e fins para a conduta, fixados por } \\
& \text { uma autoridade ou escolha, seja coletiva ou individual. Mas } \\
& \text { nenhuma filosofia fornece ou é por si mesma uma "moralidade" } \\
& \text { nesse sentido. A filosofia não está encarregada de prescrever } \\
& \text { normas ou valores: ao contrário, ela deve pensar a essência ou } \\
& \text { o sentido do que dirige a ação [l'agir] enquanto tal, em outras } \\
& \text { palavras, o que coloca a ação na posição de ter que escolher } \\
& \text { normas e valores. (NANCY, 2002, p. 66) }
\end{aligned}
$$

$\mathrm{Na}$ medida em que as correntes filosóficas da tradição metafísica abordaram os problemas que envolvem questões éticas limitadas ao ôntico, compreender que há uma instância ontológica prévia pode contribuir para a construção de um sentido de ética que possa alcançar a singularidade da vida fática. Pois é justamente para tentar evitar a armadilha metafísica que Heidegger aborda a ética remontando à origem do termo ethos, especialmente ao Fragmento 119 de Heráclito: "Ethos anthrópo daímon", interpretado pelo filósofo alemão da seguinte forma: "o homem habita, na medida em que é homem, na proximidade de Deus” (HEIDEGGER, 1973, p. 368).

Evidencia-se imediatamente a referência do termo habitar para referir-se ao ethos, e elucidar o seu significado adquire grande importância para a compreensão do novo sentido que Heidegger quer atribuir à ética. $\mathrm{Na}$ filosofia heideggeriana, pode-se dizer que "o Dasein habita um mundo de significados antes deste estar sujeito à reflexão e à organização abstrata" (HATAB, 2000, p. 20). Uma vez que o mundo depende sempre da relação de sentido que o Dasein atribui aos entes, e esta é anterior ao contato com os entes, manter-se em tal relação é o significado de habitar. Assim, o Dasein habita o seu próprio mundo enquanto ser-no-mundo, o que não pode ser descrito na relação sujeito-objeto, pressuposto este da tradição metafísica.

Da mesma forma, ao tratar do ser-em, Dreyfus descreve o habitar

Ética originária: uma reflexão para além de teoria e prática - Marcos André Webber 
como uma relação entre Dasein e mundo que não pode ser compreendida dentro das limitações da dicotomia sujeito-objeto:

\begin{abstract}
Polanyi aponta que moramos em nossa linguagem; nos sentimos em casa nela e nos relacionamos com os objetos e outras pessoas através dela. Heidegger diz o mesmo para o mundo. Habitar é o modo básico do Dasein ser-no-mundo. A relação entre mim e o que habito não pode ser compreendido no modelo da relação sujeito e objeto. (DREYFUS, 1991, p. 45)
\end{abstract}

Observe-se que justamente na descrição do habitar enquanto modo básico do ser-no-mundo está a ligação entre o ôntico e o ontológico. Se o ethos é descrito como um habitar de sentido no-mundo, que remete ao modo do Dasein ser-no-mundo, há no termo habitar uma expressão da ética situada na originariedade da comunhão com a verdade do ser. Pois é exatamente o que Heidegger explica na seguinte passagem da Carta sobre o humanismo:

Se, portanto, de acordo com a significação fundamental da palavra ethos, o nome Ética diz que medita a habitação do homem, então aquele pensar que pensa a verdade do ser como elemento primordial do homem enquanto alguém que ec-siste já é em si a Ética originária. (HEIDEGGER, 1973, p. 369)

Cabral também percebe a originariedade que Heidegger atribui ao ethos, especialmente ao destacar que a relação do Dasein com o ser é prévia à sua relação com a moral. Por consequência, uma vez que o ethos também se reveste do caráter de originariedade que liga o Dasein ao ser, pode-se dizer que o ethos deve igualmente ser compreendido como anterior à moral. Afirma Cabral:

o éthos do Dasein é mais originário do que toda moral. Se esta estipula conceitos de bem e mal e, concomitantemente, estipula costumes ou práticas para deixar vigorar ou consumar os conceitos de bem e mal anteriormente esclarecidos, é porque sua condição de possibilidade já se deu: o éthos, que funda o horizonte de sentido desde o qual aparecem todas as normas morais. Dizer, então, o amálgama ser-Dasein é já fazer uma ética originária. (CABRAL, 2009, p. 169)

$\mathrm{Na}$ interpretação de Schmidt, a ética originária heideggeriana está fundada na compreensão, a qual não pode ser explicada em termos de teoria e prática. Em outras palavras, pode-se afirmar que a compreensão não é uma técnica, e por isso o que torna a ação ética não pode ser explicado como uma questão teórica, nem como uma questão meramente de prática. Segundo o autor, 
tal ética não deveria ser compreendida como uma teoria nem uma prática, ela é, ao invés, fundada em como nós atribuímos sentido ao nosso mundo, como nós compreendemos, e isso não pode ser plenamente explicado como uma questão teórica, nem tal sentido emerge como uma questão apenas de prática. (SCHMIDT, 2012, p. 37)

Neste contexto, tomar a ética sob uma nova perspectiva exige também um rompimento com a linguagem utilizada pela tradição. Uma vez que as questões éticas surgem em situações particulares da vida fática, a linguagem deve ser capaz de alcançar a singularidade que caracteriza o Dasein. Como bem argumenta Schmidt,

a linguagem apropriada para se pensar a ética não está limitada à linguagem conceitual; em outras palavras, o filosofar não tem o monopólio sobre como é que somos capazes de tomar o enigma da vida ética. [...]. A insistência sobre a linguagem conceitual nas reflexões filosóficas sobre a ética tem levado à inapropriada ênfase sobre a ideia do imperativo como a medida ética suprema. (SCHMIDT, 2008, p. 10)

É que o saber que define a ética enquanto originária não é o mesmo saber da técnica (SCHMIDT, 2008, p. 11). Muito mais do que o conhecimento de princípios ou normas pré-estabelecidas, o comportamento ético deveria estar ligado a um modo de ser que reflita a finitude da compreensão. Neste aspecto, tanto a concepção de ética originária heideggeriana quanto a importância da experiência particular destacada por Gadamer podem contribuir para o debate ético, especialmente no sentido de elucidar o que se coloca como condição de possibilidade para a experiência da moralidade. Como bem esclarece Cabral, a ética originária visa conduzir o Dasein assumir a si próprio em sua singularidade:

A ética é originária porque ela visa conduzir o Dasein à sua raiz: sua comunhão com a verdade do ser. $\mathrm{O}$ originário da ética é, aqui, o lugar de origem de todo real, que é onde o Dasein sempre mora. Por isso, a ética originária não pode levar o Dasein a nenhum outro lugar, senão àquele em cujo seio ele sempre está. Levar o Dasein a si mesmo é tarefa da ética originária. (CABRAL, 2009, p. 163)

O que está em jogo é perceber que, se de um lado a experiência particular possibilita uma transformação no modo de ser do Dasein e na sua compreensão de mundo, na compreensão também está expressa a experiência particular de cada Dasein, que precede o contato com os entes. Uma vez que o mundo é sempre o mundo do Dasein, a experiência

Ética originária: uma reflexão para além de teoria e prática - Marcos André Webber 
particular não pode ser esquecida na relação de co-pertença entre o mundo e o Dasein. Pode-se, portanto, dizer que a experiência particular também é constitutiva do mundo, e, por este motivo, não deveria ser deixada de lado na abordagem das questões que envolvem a ética.

O modo de pensar a ética em sua relação com a verdade do ser lugar da efetiva relação entre ética e ontologia - deixa-se envolver de forma libertadora, visto que se situa para além das interpretações técnica, lógica e metafísica do pensar. O habitar coloca o homem em seu próprio lugar no mundo, e visa devolver ao homem a sua essência: que o homem seja humano (SANCHO, 2010, p. 123). Abre-se, nesta perspectiva, não apenas a possibilidade de uma nova compreensão da experiência moral, mas de entender experiencialmente o que pode ser descrito como a dignidade do ser humano.

Assim, com a ética originária, Heidegger aponta caminhos para uma compreensão de ética capaz de superar a noção da tradição metafísica, segundo a qual a ética pode ser explicada a partir de princípios e normas morais universalizáveis, e que basta aplicá-las para que se tenha uma ação moralmente válida. Ao evidenciar uma instância pré-reflexiva, prévia à relação do Dasein com normas e valores morais, a ética originária permite perceber a insuficiência da aplicação do modelo científico para a ética. A concepção de que a mera observação e aplicação de regras ou mandamentos torna moral a ação abarca apenas a esfera ôntica, mas oculta o que se coloca em um momento anterior, como condição de possibilidade da experiência da moralidade.

\section{Considerações finais}

Como buscou-se justificar no decorrer do texto, a ética originária que se encontra nos textos de Heidegger apresenta-se como uma nova noção de ética, visto que as concepções desenvolvidas pelas principais correntes ético-filosóficas têm se demonstrado insuficientes para dar conta da vida fática, a partir da qual as questões éticas emergem. Ao mesmo tempo em que rompe com o modo pelo qual a tradição metafísica tem historicamente abordado as questões acerca do tema, Heidegger indica caminhos para que se possa tratar de ética sob uma perspectiva mais radical, apontando justamente para a singularidade da relação do Dasein com o ser, que precede o contato do próprio Dasein com o mundo. É ao mesmo tempo uma recusa à objetificação da vida prática e uma tentativa de superação da distinção entre teoria e prática.

Neste contexto, a ética originária está muito mais ligada ao modo como o Dasein atribui sentido ao mundo e como ele compreende o mundo e a si próprio, o que não pode ser explicado pela linguagem objetiva universalizável da ciência ou do direito. Como destaca Schmidt, a ética

Ética originária: uma reflexão para além de teoria e prática - Marcos André Webber 
originária está ligada à formação do caráter a partir do qual emergem as relações, tanto teóricas quanto práticas, sem deixar de levar em conta a experiência particular que singulariza o Dasein em seu comportamento frente ao mundo e a si próprio.

Isso porque a noção de ética originária desvela uma esfera existencial que antecede o contato do Dasein com os entes. É que a compreensão se dá em uma instância prévia, como condição para que o Dasein tome contato com regras e valores morais. Trata-se de uma tentativa de superação da forma tradicional da filosofia conceber a ética, que não se limita a uma aplicação de regras universais - sob pena de se equiparar a uma técnica -, mas que se dá através do reconhecimento da finitude da compreensão.

A redução da ética à observação de máximas universais provoca a objetificação da vida fática, e com isso deixa-se de abarcar as fontes originárias da relação do homem com o mundo e consigo mesmo. Pensar a ética a partir da ética originária heideggeriana permite uma ampliação da reflexão filosófica sobre o tema, não apenas no que diz respeito às possíveis relações entre ética e ontologia, mas no sentido do que seja a ética enquanto tal. 


\section{Referências bibliográficas}

CABRAL, Alexandre Marques. Heidegger e a destruição da ética. Rio de Janeiro: editora UFRJ; Mauad Editora, 2009.

CAREL. Havi. The philosophical role og illness. Metaphilosophy. v. 45, n. 1, p. 20-40. jan. 2014.

DREYFUS, Hubert L. Being-in-the-World: a commentary on Heidegger's being and time, division I. Cambridge, Massachusetts: The MIT Press, 1991. . What is moral maturity? A phenomenological account of the development of ethical expertise. Disponível em socs.berkeley.edu/ hdreyfus/rtf/Moral_Maturity_8_90.rtf. Acesso em 09. Ago. 2016.

DUTT, Carsten. En Conversación con Hans-Georg Gadamer (Hermenéutica - Estética - Filosofía Prática). Trad. de Teresa Rocha Barco. Madrid: Tecnos, 1998.

GADAMER, Hans-Georg. El estado oculto de la salud. Barcelona: Gedisa Editorial, 2001.

Verdade e método I. Trad. de Flávio Paulo Meurer; rev. trad. de Enio Paulo Giachini. 11. ed. Petrópolis, RJ: Vozes. Bragança Paulista: Editora Universitária São Francisco, 2011.

HATAB, Lawrence J. Ethics and finitude: Heideggerian contributions to moral philosophy. Maryland: Rowman and Littlefield Publishers, 2000.

HEIDEGGER, Martin. Carta sobre o Humanismo. Trad. de Ernildo Stein. São Paulo: Abril S/A Cultural e Industrial, 1973.

2006. . Sein und Zeit. 19. ed. Tübingen: Max Niemeyer Verlag,

LOPARIC, Zeljko. Ética e finitude. 2. ed. rev. e ampl. São Paulo: Editora Escuta, 2004.

NANCY, Jean-Luc. Heidegger's “originary ethics". In: RAFFOUL, François; PETTIGREW, David. Heidegger and practical philosophy. Albany: State University of New York Press, 2002.

SANCHO, Jesús Conill. Ética hermenêutica. 2. ed. Madrid: Tecnos, 2010.

SCHMIDT, Dennis J. Hermeneutics as original ethics. Difficulties of Ethical Life. New York: Fordham University Press, 2008. . On the Sources of Ethical Life. Research in Phenomenology,

v. 42, p. 35-48, 2012. Disponível em
http://booksandjournals.brillonline.com/content/journals/10.1163/15691641 2x628739. Acesso em 07. Ago. 2016. 